\section{Association Between the Angiotensinogen Gene Polymorphism and The Pro-Oxidant Effect in Tunisian Patients with Coronary Heart Disease} Dandana $A^{1 *}$, Khelifa SB ${ }^{1}$, Bouzidi N1, Addad F ${ }^{2,3}$ and Ferchichi $\mathbf{S}^{1}$

${ }^{1}$ Laboratory of Biochemistry, Farhat Hached Hospital, Sousse, Tunisia

${ }^{2}$ Department of Cardiology, Abderrahmane Mami Hospital, Ariana, Tunisia

${ }^{3}$ Department of Cardiology CHU-Fattouma Bourguiba Monastir, Tunisia

\begin{abstract}
Background: Evaluation and investigation of the pro-oxidant role of the angiotensinogen (AGT) among Tunisian coronary.

Materials and methods: The current study evaluated the frequency of AGT (M235T and A(-6)G) polymorphism in relation to coronary artery disease in a group of Tunisian population. AGT polymorphism was determined by Real Time PCR. These subjects (150 patients and 120 controls) beneficed also by an enzymatic determination of superoxide dismutase (SOD), glutathione peroxidase (GPX), total antioxidant status (TAS), catalase (CAT) activity was determined spectrophotometrically and serum lipid peroxides were measured by the fluorimetric method reaction to reveal the atherogenic effects of these radical species and investigate their interactions with AGT polymorphisms.

Results: The results revealed that there was a positive risk of developing coronary artery disease when having the $T$ allele whether in homozygous or heterozygous state. Statistical tests of the baseline correlation between oxidative stress parameters and M235T genotype groups showed a negative correlation between MM genotype group and oxidant parameters (SOD, GPX and TAS). The same result was found in TT and MT genotype groups.

Conclusion: This study shows that the AGT polymorphisms were associated with the presence of coronary artery disease. In addition to its vasoconstrictor role, AGT can be considered as a pro-oxidant, these two effects combine in the genesis and the complications of cardiovascular diseases.
\end{abstract}

Keywords: Angiotensinogen; Hypertension; Endothelial dysfunction; Polymorphism; Coronary artery disease; oxidative stress

\section{Introduction}

Oxidative stress has been suggested to be involved in the pathogenesis of hypertension. It is a pathological condition that increases the risk of developing hypertension [1]. Oxidative stress occurs when the production of Reactive oxygen species (ROS) overwhelms the antioxidant capacity resulting in overall damage to cells and has been implicated in the pathology of many hypertensives, a hypoxic environment being essential for trophoblast proliferation and invasion of the maternal spiral arteries for the restructuring of these blood vessels [2].

The ROS are molecule produced from the reduction of molecular oxygen, generated as by-products of aerobic respiration and metabolism [2]. ROS plays an important role in the development of cardiovascular disease, including hypertension, atherosclerosis, diabetes, cardiac hypertrophy, heart failure, ischemia reperfusion injury and stroke [3].

ROS are produced by various oxidase enzymes, including nicotinamide-adenine dinucleotide phosphate (NADPH) oxidase, xanthine oxidase, uncoupled endothelial nitric oxide (NO) synthase (eNOS), cyclo-oxygenase, glucose oxidase, and lipooxygenase, and mitochondrial electron transport. ROS include superoxide anion $\left(\mathrm{O}^{2-}\right.$ ), hydrogen peroxide $\left(\mathrm{H}_{2} \mathrm{O}_{2}\right)$, hydroxyl radical $(\mathrm{OH})$, hypochlorous acid $(\mathrm{HOCl}), \mathrm{NO}$, and peroxynitrite $\left(\mathrm{ONOO}^{-}\right) . \mathrm{O}^{2-}, \mathrm{OH}$, and $\mathrm{NO}$ are classified as free radicals that have unpaired electrons and potent oxidation ability. $\mathrm{H}_{2} \mathrm{O}_{2}, \mathrm{HOCl}$, and $\mathrm{ONOO}^{-}$are classified as non-free radicals that also have oxidation ability. The sources of ROS are a variety of cell types, including vascular smooth muscle cells (VSMCs), endothelial cells and mononuclear cells. The antioxidant enzyme superoxide dismutase (SOD) has been identified as 3 enzymatic types: $\mathrm{Cu} / \mathrm{Zn}$ SOD, Mn SOD, and extracellular SOD. SOD rapidly dismutates
$\mathrm{O}^{2-}$ to $\mathrm{H}_{2} \mathrm{O}_{2}$, and then $\mathrm{H}_{2} \mathrm{O}_{2}$ is eliminated by glutathione peroxidase (GPX) and catalase to water [4].

Endothelial dysfunction is an important early step in atherosclerosis and it precedes the morphological changes that occur to the arterial wall [2].

The term endothelial dysfunction has been used to refer to several pathological conditions, including altered anticoagulant and antiinflammatory properties of the endothelium, impaired modulation of vascular growth, and deregulation of vascular remodeling [5].

However, in much of the literature this term has been used to refer to an impairment of endothelium- dependent vasorelaxation caused by a loss of NO bioactivity in the vessel wall [6]. Various vasodilators, including NO, prostacyclin, and endothelium-derived hyperpolarizing factor (EDHF), as well as vasoconstrictors, are released from the endothelium [4].

Several pathological Conditions can lead to impairment of endothelial function including: diabetes, hypertension, metabolic syndrome, coronary artery disease, obesity and rheumatoid arthritis [7].

*Corresponding author: Dr. Azza Dandana, Laboratory of Biochemistry Farhat Hached Hospital, Street Doctor Moreau, 4000 Sousse, Tunisia, Tel: 21673219503 Fax: 216 73226702, E-mail: azzadandana@yahoo.fr

Received July 08, 2016; Accepted October 25, 2016; Published October 28, 2016

Citation: Dandana A, Khelifa SB, Bouzidi N, Addad F, Ferchichi S (2016) Association Between the Angiotensinogen Gene Polymorphism and The ProOxidant Effect in Tunisian Patients with Coronary Heart Disease. J Mol Genet Med 10: 230 doi:10.4172/1747-0862.1000230

Copyright: (c) 2016 Dandana A, et al. This is an open-access article distributed under the terms of the Creative Commons Attribution License, which permits unrestricted use, distribution, and reproduction in any medium, provided the original author and source are credited 
The multimeric enzyme complex NAD(P)H oxidase, or Nox, is the major enzyme system that generates superoxide in the vasculature. A major physiological activator is angiotensin II (ANG II), acting on AT1 receptors and then protein kinase $\mathrm{C}$ to stimulate Nox [8].

Oxidative stress is a pathological condition that increases the risk of developing hypertension. Several studies have indicated that many of the cardiovascular $(\mathrm{CV})$ risk factors that predispose to the development of atherosclerosis, such as hypertension, diabetes and hypercholesterolemia, are also associated with endothelial dysfunction [8].

The analysis of renine angiotensin system (RAS) related genetic polymorphism of patients having cardiovascular disease (CVD) has been carried out in Tunisian population on a limited scale. So, this study aimed to determine the association of genetic polymorphisms of the angiotensinogen ( $M 235 T$ and $\mathrm{A}(-6 \mathrm{G})$ ) gene with coronary artery disease in a cohort of genetically homogenous CVD patients and controls (case-control study) and investigate its pro-oxidant effect on these patients by measuring the markers of the first line of defense against aggression radical, superoxide dismutase (SOD), glutathione peroxidase (GPX), the total antioxidant status (TAS) and also by quantifying pro-oxidant parameters (homocysteine and Lipid peroxides as malodialdehyde).

\section{Materials and Methods}

\section{Study group}

The study population consists of two groups. The control subjects are 120 healthy volunteers ( 80 men and 40 women) with no history of cardiovascular disease (CVD), diabetes or cerebrovascular diseases. Their mean age is $40 \pm 7$ years. 150 consecutive patients ( 115 men and 35 women) with angiographically documented CVD were enrolled from Cardiovascular Department of University Hospital Fattouma Bourguiba of Monastir, Tunisia. The mean age of this group is $61.15 \pm$ 10.64 years.

All patients admitted to our study had a history of stable angina defined by the presence of chest pain or unstable angina and were found to have Coronary artery disease $(\mathrm{CAD})$ at angiography. Two experienced cardiologists, unaware of patient's clinical history and biochemical results, visually assessed all angiograms to assess the extent of the CAD. Patients with severe renal dysfunction, life-threatening arrhythmias, acute and chronic liver disease, infectious and inflammatory disease, and symptomatic heart failure were excluded. The detailed histories of patients included demographics data, and cardiovascular risk factors were recorded. All participants were interviewed, and data on dyslipidemia, diabetes mellitus, hypertension, and smoking habits were recorded. For coronary risk factors, the following definitions were used: individuals were defined as hypertensive if their blood pressure was $>140 / 90 \mathrm{mmHg}$ or if they were receiving any antihypertensive treatment; individuals with a history of diabetes mellitus or those receiving any antidiabetic medication were considered to be diabetic; individuals were deemed dyslipidemic if their total cholesterol (TC) concentration was $\geq 5.68 \mathrm{mmol} / \mathrm{l}$, or their triglyceride (TG) concentration was $\geq 2.28$ $\mathrm{mmol} / \mathrm{l}$, or they were receiving lipid-lowering drugs. Smoking history was coded as never and current smoker.

\section{Methods}

\section{Laboratory analysis}

Measurement of biochemical variables Levels of TC, TG, highdensity lipoprotein cholesterol (HDLc), and serum creatinine were measured using standardized enzymatic methods (Randox-Antrim,
UK). In Addition, Serum high sensitive C- reactive protein (hs-CRP), fibrinogen, cystatin $\mathrm{C}$ and serum apolipoproteins (ApoA1 and ApoB), were quantified according to the instructions of the manufacture using particle-enhancer immunonephelometric assays (BNII Dade Behring, Marburg, Germany).

\section{Determination of oxidative stress parameters}

Determination of the oxidative state markers SOD, GPX, glutathione reductase (GR), activities, and total antioxidant status (TAS) concentration were checked using commercials tests manufactured by Randox Laboratories (Antrim, UK) in a Daytona analyser. The catalase (CAT) activity was determined spectrophotometrically as the rate of substrate decomposition per unit time [9]. Serum lipid peroxides were measured by the fluorimetric method of Yagi [10] using thiobarbituric acid reaction (Ex $515 \mathrm{~nm}$, Em $553 \mathrm{~nm}$ ) [11]. Homocysteine was quantified according to the instructions of the manufacture using particle-enhancer immunonephelometric assays (BNII Dade Behring, Marburg, Germany).

\section{Determination of M235T, A(-6)G, A(-20)G by Real Time PCR}

Detection of M235T, A(-6)G, A(-20)G polymorphisms were carried out by Real Time PCR (MyiQTm, BIO RAD). PCR and melting curve analysis were performed using $300 \mathrm{ng}$ of DNA, PCR mastermix (iQTm SYBR $^{\circ}$ Green Supermix), and a mix of these different allele specific primer [(M235T : Forward: 5’AGC AGA GAG GTT TGC CTT ACC T 3'; Reverse 1: 5'GTT CAT GCA GGC TGT GAC AGC TTG GAA GAC TGG CTG CTC CCT CAT 3'; Reverse 2: 5'GAT GGA AGA CTG GCT GCT CCC AGA C 3') and (A(-6)G: Forward: 5' GTG TCG CTT CTG GCA TCT GTC CTT CTG G 3'; Reverse 1: 5’TAC CCA GAA CAA CGG CAG CTT CTT CCA CT 3'; Reverse 2 : 5'CCG GTT ACC TTC TGC TGT AGA GCC CAG AAC AAC GGC AGC TTC TTC CAT C3')] $[12,13]$. The cycling program involves a first denaturation step $\left(3 \mathrm{~min}\right.$ at $95^{\circ} \mathrm{C}$ ) was followed by 40 cycles (each of $20 \mathrm{~s}$ at $65^{\circ} \mathrm{C}$ and 40 $\mathrm{s}$ at $60^{\circ} \mathrm{C}$ ), 3 minutes at $95^{\circ} \mathrm{C}$ and by 4 minutes at $55^{\circ} \mathrm{C}$. Melting curve analysis shows the temperature at which a double- stranded amplicon dissociates into single-stranded DNA, thus releasing the SYBRGreen I resulting in decrease inflorescences.

\section{Statistical analysis}

Database management and statistical analyses were carried out using SPSS (Statistical Package for the Sociological Sciences), version 15.0. Results are presented as means $\pm \mathrm{SD}$, or percentages. Means were compared using Student test. The relations between variables were assessed with Pearson's correlation analysis. The significance threshold was set at $5 \%(\mathrm{p}<0.05)$.

\section{Results}

Baseline characteristics of 270 participants (150 patients and 120 controls) used in this analyze are presented in Table 1 . Among 150 participants, there were 115 men and 40 women and $49 \%$ of the women were on hypertension. Statistical data processing still significantly lower TAS, GPX, and CAT among patients compared to the controls (Table 1). Lipid markers (LDLc, HDLc, and Total cholesterol) showed significant differences between patients and controls $(\mathrm{p}<0.05)$. ApoB, hsCRP, fibrinogen concentrations were significantly elevated in patients compared to controls (Table 1).

In our study, a statistically significant elevation of the first line antioxidant parameters (SOD, GPX) was found among patients compared with controls. In other hand, the oxidant parameters 


\begin{tabular}{|c|c|c|c|c|}
\hline & & Patients & Controls & ANOVA \\
\hline \multirow{2}{*}{ Gender } & & 115 men & 80 men & \\
\hline & & 35 women & 40 women & \\
\hline Age & Years $(X \pm \delta)$ & $61.15 \pm 10.64$ & $40 \pm 7$ & $p<0.05$ \\
\hline Total cholesterol & $\mathrm{mmol} / \mathrm{l}(\mathrm{X} \pm \delta)$ & $5.97 \pm 1.12$ & $3.6 \pm 0.45$ & $p<0.05$ \\
\hline HDL-C & $\mathrm{mmol} / \mathrm{l}(\mathrm{X} \pm \delta)$ & $1.3 \pm 0.45$ & $1 \pm 0.37$ & $p<0.05$ \\
\hline LDL-C & $\mathrm{mmol} / \mathrm{l}(\mathrm{X} \pm \delta)$ & $3.75 \pm 0.98$ & $1.88 \pm 0.8$ & $p<0.01$ \\
\hline Apo (A1) & $g / l(X \pm \delta)$ & $1.21 \pm 0.98$ & $1.55 \pm 0.28$ & $p<0.01$ \\
\hline Apo (B) & $g / l(X \pm \delta)$ & $1.45 \pm 0.5$ & $0.86 \pm 0.22$ & $p<0.01$ \\
\hline Cystatin C & $\mathrm{mg} / \mathrm{l}(\mathrm{X} \pm \delta)$ & $0.95 \pm 0.67$ & $0.73 \pm 0.14$ & $p<0.05$ \\
\hline Creatinine & $\mu \mathrm{mol} / \mathrm{l}(\mathrm{X} \pm \delta)$ & $80.02 \pm 30.31$ & $62.77 \pm 13.08$ & $p<0.01$ \\
\hline hsCRP & $\mathrm{mg} / \mathrm{l}$ & $7.6 \pm 0.8$ & $2.09 \pm 0.34$ & $p<0.05$ \\
\hline Fibrinogen & $g / l(X \pm \delta)$ & $3.9 \pm 1.39$ & $2.61 \pm 0.51$ & $p<0.01$ \\
\hline GPX & $\mathrm{U} / \mathrm{gHb}(\mathrm{X} \pm \delta)$ & $59.33 \pm 10.72$ & $149.23 \pm 30.95$ & $p<0.01$ \\
\hline $\mathrm{GR}$ & $\mathrm{U} / \mathrm{gHb}(\mathrm{X} \pm \delta)$ & $2.45 \pm 0.86$ & $6.7 \pm 1.13$ & $p<0.01$ \\
\hline CAT & $\begin{array}{c}\mu \mathrm{mol} \mathrm{H}_{2} \mathrm{O}_{2} / \mathrm{min} / \\
\mathrm{mg} \text { proteins }(\mathrm{X} \\
\pm \delta)\end{array}$ & $1.05 \pm 0.1$ & $2.33 \pm 0.32$ & $p<0.01$ \\
\hline SOD & $\mathrm{U} / \mathrm{gHb}(\mathrm{X} \pm \delta)$ & $\begin{array}{l}649.58 \pm \\
392.033\end{array}$ & $\begin{array}{c}1378.47 \pm \\
360.95\end{array}$ & $p<0.01$ \\
\hline TAS & $\mathrm{mmol} / \mathrm{l}(\mathrm{X} \pm \delta)$ & $1.85 \pm 0.35$ & $0.66 \pm 0.31$ & $p<0.05$ \\
\hline $\begin{array}{l}\text { Lipid peroxides as } \\
\text { malodialdehyde }\end{array}$ & $\mu \mathrm{mol} / \mathrm{l}(\mathrm{X} \pm \delta)$ & $13.36 \pm 5.52$ & $7.88 \pm 2.15$ & $p<0.01$ \\
\hline Homocysteine & $\mathrm{mmol} / \mathrm{l}(\mathrm{X} \pm \delta)$ & $1.14 \pm 0.28$ & $1.55 \pm 0.28$ & $p<0.05$ \\
\hline
\end{tabular}

Table 1: General characteristics for the entire group.

\begin{tabular}{|c|c|c|c|}
\hline \multicolumn{4}{|c|}{ MM Genotype Group } \\
\hline & & Hcy & Lipid peroxide as malodialdehyde \\
\hline \multirow{3}{*}{ SOD } & $\mathrm{r}$ & -1.125 & -1.08 \\
\hline & $\mathrm{p}$-value & 0.02 & 0.04 \\
\hline & $N$ & 102 & 102 \\
\hline \multirow{3}{*}{ GPX } & $\mathrm{r}$ & -1.074 & -1.085 \\
\hline & $\mathrm{p}$-value & 0.03 & 0.04 \\
\hline & $\mathrm{N}$ & 102 & 102 \\
\hline \multirow{3}{*}{ CAT } & $\mathrm{r}$ & -1.125 & -1.02 \\
\hline & $\mathrm{p}$-value & 0.01 & 0.03 \\
\hline & $\mathrm{N}$ & 102 & 102 \\
\hline \multirow{3}{*}{ SAT } & $\mathrm{r}$ & -1.133 & -1.074 \\
\hline & $p$-value & 0.01 & 0.04 \\
\hline & $\mathrm{N}$ & 102 & 102 \\
\hline \multicolumn{4}{|c|}{ TT + MT Genotype Group } \\
\hline & & Hcy & Lipid peroxide as malodialdehyde \\
\hline \multirow{3}{*}{ SOD } & $\mathrm{r}$ & -1.254 & -1.240 \\
\hline & $p$-value & 0.032 & 0.008 \\
\hline & $\mathrm{N}$ & 53 & 53 \\
\hline \multirow{3}{*}{ GPX } & $\mathrm{r}$ & -1.118 & -1.054 \\
\hline & $\mathrm{p}$-value & 0.011 & 0.023 \\
\hline & $\mathrm{N}$ & 53 & 53 \\
\hline \multirow{3}{*}{ CAT } & $\mathrm{r}$ & -1.321 & -1.11 \\
\hline & $\mathrm{p}$-value & 0.033 & 0.015 \\
\hline & $\mathrm{N}$ & 53 & 53 \\
\hline \multirow{3}{*}{ SAT } & $\mathrm{r}$ & -1.103 & -1.159 \\
\hline & $p$-value & 0.26 & 0.025 \\
\hline & $\mathbf{N}$ & 53 & 53 \\
\hline
\end{tabular}

Table 2: Baseline correlation between oxidative stress parameters by M235T genotype group.

(Homocysteine and Lipid peroxides as malodialdehyde), were statistically elevated in controls compared to controls (Table 1).

Table 2 summarized the baseline correlation between oxidative stress parameters and M235T genotype groups. Among MM genotype group, our results suggested a negative correlation between antioxidant and oxidant parameters. The same result was found in TT and MT genotype group (Table 2).

In Table 3, there were significant differences at the baselines between genotype groups for the M235T polymorphism for any of the oxidative stress variables and lipid markers $(\mathrm{p}<0.05)$ (Table 3$)$.

In light of previous reports of associations between the M235T polymorphism, predicting high risk and low risk AGT polymorphism (M235T and $\mathrm{A}(-6) \mathrm{G})$ genotype combination were determinate and comparisons were made between the groups (Tables 4 and 5).

\section{Discussion}

There is equilibrium between ROS formation and endogenous antioxidant defense mechanisms. But when this balance is disturbed, it can lead to oxidative stress. This state of oxidative stress can result in injury to all the important cellular components such as proteins, DNA and membrane lipids which can lead to cell death. Endothelial dysfunction is a common accompaniment in several diseases [14].

CVD is a class of diseases that involves several traditional risk factors that tend to aggregate together possibly because of a common underlying cause [15-17]. Essential hypertension is one of the major risk factors for CVD and is considered to be a large public health issue due to the fact that it affects $\sim 25-35 \%$ of the adult population $[18,19]$.

Recent studies also began the study of pro-oxidant role of the AGT by activation of NADPH oxidase which triggers lipid peroxidation starting point for atherosclerosis.

General characteristics and oxidative stress parameters activities were mentioned in Table 1 . The correlation between oxidative stress parameters by $M 235 T$ genotype group in patient's population were presented in Table 2. Hyperactivity of these enzymes may reflect a kind of adaptive response towards a state of imbalance pro-oxidant/ antioxidant; these enzymes must act to reduce the amplification rate of radical species. Some studies explain the rise in the activity of these enzymes by a genetic regulation mediated by redox sensitive transcription factors such as Nrf2 (nuclear factor-erythroid-2 p45related factor) $[20,21]$.

Although the measure of the TAS quantifies the cumulative action of antioxidants in the human body, this status was significantly decreased in patients compared to controls which brings us back to promote the role of other antioxidants (enzymatic and non-enzymatic antioxidants) and confirms the oxidative imbalance theory, this is a deficiency in the total antioxidant activity in patients $[22,23]$.

\begin{tabular}{|c|c|c|c|c|}
\hline & & \multicolumn{2}{|c|}{ M235T Genotype } & \multirow{2}{*}{ p-value } \\
\hline Age & Years & 58.6 & 62.57 & $\mathrm{p}<0.05$ \\
\hline $\mathrm{BMI}$ & $\mathrm{Kg} / \mathrm{m}^{2}(\mathrm{X} \pm \delta)$ & 33.7 & 27.8 & $\mathrm{~ns}$ \\
\hline $\mathrm{HDL}-\mathrm{c}$ & $\mathrm{mmol} / \mathrm{l}(\mathrm{X} \pm \delta)$ & 1.033 & 1.5 & $\mathrm{p}<0.05$ \\
\hline $\mathrm{LDL}-\mathrm{C}$ & $\mathrm{mmol} / \mathrm{l}(\mathrm{X} \pm \delta)$ & 4.6 & 3.3 & $\mathrm{p}<0.05$ \\
\hline $\mathrm{GPX}$ & $\mathrm{U} / \mathrm{gHb}(\mathrm{X} \pm \delta)$ & $68 \pm 11$ & $58.3 \pm 10.5$ & $\mathrm{p}<0.05$ \\
\hline $\mathrm{GR}$ & $\mathrm{U} / \mathrm{gHb}^{\prime}(\mathrm{X} \pm \delta)$ & $1.42 \pm 0.81$ & $2.51 \pm 0.95$ & $\mathrm{p}<0.05$ \\
\hline $\mathrm{CAT}$ & $\begin{array}{c}\mu \mathrm{mol} \mathrm{H}_{2} \mathrm{O}_{2} / \mathrm{min} / \mathrm{mg} \\
\mathrm{proteins}(\mathrm{X} \pm \delta)\end{array}$ & $1.05 \pm 0.12$ & $1.06 \pm 0.06$ & $\mathrm{NS}$ \\
\hline $\mathrm{SOD}$ & $\mathrm{KU} / \mathrm{gHb}(\mathrm{X} \pm \delta)$ & $8.65 \pm 0.34$ & $4.56 \pm 0.42$ & $\mathrm{p}<0.05$ \\
\hline $\mathrm{TAS}$ & $\mathrm{mmol} / \mathrm{I}(\mathrm{X} \pm \delta)$ & $2.16 \pm 0.27$ & $0.12 \pm 0.3$ & $\mathrm{p}<0.001$ \\
\hline $\begin{array}{c}\text { Lipid } \\
\text { peroxides as } \\
\text { malodialdehyde }\end{array}$ & $\mu \mathrm{mol} / \mathrm{l}(\mathrm{X} \pm \delta)$ & $0.8 \pm 0.34$ & $3.9 \pm 0.36$ & $\mathrm{p}<0.05$ \\
\hline Homocysteine & $\mathrm{mmol} / \mathrm{l}(\mathrm{X} \pm \delta)$ & $18.4 \pm 5.26$ & $13.35 \pm 6$ & $\mathrm{p}<0.05$ \\
\hline
\end{tabular}

Table 3: Baseline characteristics of study genotype for M235T polymorphism. 
The hypothesis suggests the role of ROS generated following the activation of NADPH oxidase in the destabilization and damage to the endothelium which leads to the diminution of its secretion and therefore its activity, to other hand, the TAS was exhausted by the various toxic and pro-oxidant effects triggered during the oxidative imbalance $[24,25]$.

The negative correlations between M235T genotype group and oxidative stress enzymes (SOD, GPX and TAS) can be explained by the pro-oxidant effect of the AGT, since ANG II stimulated superoxide production results in impairment of the balance between relaxing and contracting factors released from the endothelium, leading to endothelial damage and hypertension [26]. ANG II has also been shown to increase superoxide formation in models of ANG II- induced hypertension and in vascular smooth muscle cells [27-29]. There is also evidence to suggest a role of NADPH oxidase enzymatic complex in ANG II-induced oxidative stress.

Moreover, the $\mathrm{T}$ allele was highly associated with cardiovascular risk factors such as hs-CRP, LDL-c and with the prooxidant parameters (lipid peroxides as malonaldialdehyde and homocysteine), than $\mathrm{M}$ allele (Table 3).

Jeunemaitre et al. [30] were the first to report the linkage of the molecular variant M235T with hypertension in Whites/Caucasians. Subsequent studies among Whites/Caucasians supported an association [31] while others did not support any association [32,33] such as and in a Tunisian cohort. The association between AGT M235T polymorphism heart failure seems confirmed and the clinical as the genetic of this Tunisian population and the AGT M235T polymorphism is a good independent predictor for prognosis at one year [34].

In our study, the cardiovascular risk factors were greatest associated with the AA genotype of the AGT T235 and the AGT G-6A polymorphism and lowest in those with M235 and the GG genotype (Tables 4 and 5).

In addition, there is a methionine-to-threonine transition, caused by a T3C single nucleotide polymorphism (SNP) at codon 235 (M235T) in the proximal promoter. Although this polymorphism has been definitively excluded as the functional variant by biochemical analysis of recombinant M235 and T235 molecules [35], it is in very tight linkage equilibrium with AGT G-6A and is associated with higher concentrations of AGT [36], with hypertension phenotypes [37-40], and with identical associations in intervention trials [41].

\begin{tabular}{|c|c|c|c|c|}
\hline $\begin{array}{c}\text { Allele } \\
\text { combinations }\end{array}$ & $235 T /-6 A$ & $235 T /-6 G$ & $235 \mathrm{C} /-6 \mathrm{~A}$ & $235 \mathrm{C} /-6 \mathrm{G}$ \\
\hline \multirow{2}{*}{$235 \mathrm{~T} /-6 \mathrm{~A}$} & TTAA & TTAG & TCAA & \multirow{2}{*}{-} \\
\hline & $(n=51)$ & $(n=6)$ & $(n=43)$ & \\
\hline \multirow{2}{*}{$235 T /-6 G$} & \multirow{2}{*}{-} & MMGG & TCGA & TCGG \\
\hline & & $(n=45)$ & $(n=6)$ & $(n=52)$ \\
\hline \multirow{2}{*}{$235 \mathrm{C} /-6 \mathrm{~A}$} & \multirow{2}{*}{-} & \multirow{2}{*}{ - } & CCAA & CCAG \\
\hline & & & $(n=32)$ & $(n=2)$ \\
\hline \multirow{2}{*}{$235 \mathrm{C} /-6 \mathrm{G}$} & \multirow{2}{*}{-} & \multirow{2}{*}{ - } & \multirow{2}{*}{ - } & CCGG \\
\hline & & & & $(n=17)$ \\
\hline
\end{tabular}

Table 4: Distribution of AGT genotype combinations and risk allele groups M235T (T/G).

\begin{tabular}{|c|c|c|c|}
\hline Group & \# of Risk Alleles & Genotype combination & N \\
\hline 1 & 0 or 1 & TTAA. TTAG. TTGG & 102 \\
\hline 2 & 2 & TCAA. TCGA. TCGG & 101 \\
\hline 3 & $\geq 3$ & CCAA. CCAG. CCGG & 51 \\
\hline
\end{tabular}

Table 5: AGT risk allele groups.
Jeunemaitre et al. [30] suggested that the distribution of GT alleles, as well as the presence of multiple site polymorphisms on haplotypes carrying both T235 and A-6, suggest that T235 and A- 6 may mark the original form of the gene. This interpretation is supported further by the presence of this form of the gene in all primate species examined.

The mechanism by which the molecular variant M235T allele of the AGT gene is related to hypertension is poorly understood. Although the AGT 235T allele was found to be in complete linkage disequilibrium with a guanine to adenosine transition at $-6 \mathrm{bp}$ upstream of the initiation site of transcription [35]

In vitro test of promoter activity and DNA binding studies with nuclear proteins show that this nucleotide substitution affects the basal transcription rate of the gene in various cell lines there by affecting the AGT T235 variant, increased plasma AGT levels that might lead to increased blood pressure [30].

This study suggests the existence of a linkage between AGT gene polymorphism and the pathogenesis of cardiovascular diseases. These findings might help to manipulate the therapeutic strategies in those cases as the potential for utility of genetic characterization of individual patients as a predictor of antihypertensive response has been realized.

\section{Conclusion}

The population under study does not conform to the HardyWeinberg equilibrium theory which means some evolutionary forces are acting on the locus under consideration. The results obtained from this study will form baseline information for these areas but more work still needs to be carried out to look for other gene polymorphisms that could be positive predictors for hypertension in this population.

\section{Acknowledgments}

The authors thank the staff of the biochemistry laboratory and the department of cardiology in university hospital, Fattouma Bouguiba of Monastir for their valuable contribution in this work.

\section{Competing Interests}

Non-financial competing interests (political, personal, religious, ideological academic, intellectual, commercial or any other) to declare in relation to this manuscript.

\section{References}

1. Virdis A, Duranti E, Taddei S (2011) Oxidative stress and vascular damage in hypertension: Role of Angiotensin II. Res Inter J Hyper 2011: 1-7.

2. Silva BR, Pernomian L, Bendhack LM (2012) Contribution of oxidative stress to endothelial dysfunction in hypertension. Front Physiol 5(3): 441.

3. Wang D, Chen Y, Chabrashvili T, Aslam S, Borrego LJ, et al. (2003) Role of oxidative stress in endothelial dysfunction and enhanced responses to angiotensin II of afferent arterioles from rabbits infused with angiotensin II. J Am Soc Nephrol 14: 2783-2789.

4. Tsilimingas N, Warnholtz A, Wendt M, Mnzel T (2004) Angiotensin II and oxidative stress.

5. Kon K, Chun OP, Quon MJ (2009) Does reversal of oxidative stress and inflammation provide vascular protection? Cardio Res 81: 649-659.

6. He F, Zuo L (2015) Redox roles of reactive oxygen species in cardiovascular diseases. Int J Mol Sci 16: 27770-27780.

7. Cai H, Harrison DG (2000) Endothelial dysfunction in cardiovascular diseases. The role of oxidant stress. Circ Res 87: 840-844.

8. Ritz E, Haxsen V (2003) Angiotensin II and oxidative stress: An unholy alliance J Am Soc Nephrol 14: 2985-2987.

9. Aebi H (1984) Catalase in vitro. Methods Enzymol 105: 121-126.

10. Yagi K (1984) Assay for blood plasma or serum. Methods Enzymol 105: 328-331. 
Citation: Dandana A, Khelifa SB, Bouzidi N, Addad F, Ferchichi S (2016) Association Between the Angiotensinogen Gene Polymorphism and The Pro-Oxidant Effect in Tunisian Patients with Coronary Heart Disease. J Mol Genet Med 10: 230 doi:10.4172/1747-0862.1000230

Page 5 of 5

11. Davis BJ (1964) Disc electrophoresis II, methods and application to human serum proteins. Ann N Y Acad Sci 121: 404-427.

12. Rust S, Funke H, Assmann G (1993) Mutagenically separated PCR (MSPCR): A highly specific one step procedure for easy mutation detection. Nucl Acids Res 21: 3623-3629.

13. Dandana A, Gammoudi I, Ferchichi S, Chahed H, Bricca G (2011) Real time $\mathrm{PCR}$ for fast detection of the angiotensinogen polymorphism. Ann Biol Clin 69(4): 447-451.

14. Briones AM, Touyz RM (2010) Oxidative stress and hypertension: Current concepts. Curr Hypertens Rep 12(2): 135-142.

15. Lim LS, Haq N, Mahmood S, Hoeksema L (2011) The ACPM Prevention Practice Committee. Atherosclerotic cardiovascular disease screening in adults. American College of Preventive Medicine Position Statement on Preventive Practice. Am J Prev Med 40(3): 380 -381.

16. http: //circ.ahajournals.org/content/circulationaha/early/2008/12/15/Circulation AHA.108.191261.full.pdf

17. Berger JS, Jordan CO, Lloyd-Jones D, Blumenthal RS (2010) Screening for cardiovascular risk in asymptomatic patients. J Am Coll Cardiol 55(12): $1169-1177$.

18. Kunes J, Zicha J (2009) The interaction of genetic and environmental factors in the etiology of hypertension. Physiol Res 58: S33-41.

19. Kooffreh ME, Anumudu Cl, Akpan EE, Ikpeme EV, Kumar LP (2012) A study of the M235T variant of the angiotensinogen gene and hypertension in a sample population of Calabar and Uyo, Nigeria. Egypt J Med Hum Genet 14: 13-19.

20. Bartosz G (2009) Reactive oxygen species: Destroyers or messengers? Biochem Pharmacol 77: 1303-1315.

21. Senthil S, Veerappan RM, Ramakrishna R, Pugalendi KV (2004) Oxidative stress and antioxidants in patients with cardiogenic shock complicating acute myocardial infarction. Clin Chim Acta 348: 131-137.

22. Michel F, Bonnefont-Rousselot D, Mas E, Drai J, Thérond $P$ (2008) Biomarkers of lipid peroxidation: Analytical aspects. Ann Biol Clin 66: 605-620.

23. Shahin J, Alam KJ, Nehemiah S, Chatter I (2011) Angiotensin converting enzyme inhibitors effect on endothelial dysfunction: A meta-analysis of randomised controlled trials. Atherosclerosis 216: 7-16.

24. Franco AA, Odom RS, Rando TA (1999) Regulation of anti-oxidant enzyme gene expression in response to oxidative stress and during differentiation of mouse skeletal muscle. Free Radical Bio Med 27: 1122-1132.

25. Landmesser U, Harrison DG (2001) Oxidative stress and vascular damage in hypertension. CAD 12(6): 455-461.

26. Milstien S, Katusic Z (1999) Oxidation of tetrahydrobiopterin by peroxynitrite: Implications for vascular endothelial function. Biochem Biophys Res Commun 263: 681-684.
27. Zhou MS, Jaimes EA, Raij L (2004) Inhibition of oxidative stress and improvement of endothelial function by amlodipine in angiotensin II-infused rats. Am J Hypertens 17: 167-171.

28. Schiffrin EL (2001) A critical review of the role of endothelial factors in the pathogenesis of hypertension. J Cardiovasc Pharmacol 38: S3-S6.

29. Park JB, Charbonneau F, Schiffrin EL (2001) Correlation of endothelial function in large and small arteries in human essential hypertension. J Hypertens 19 415-420.

30. Jeunemaitre $X$, Soubrier F, Kotelevtsev YV, Lifton RP, Williams CS, et al. (1992) Molecular basis of human hypertension: Role of angiotensinogen. Cell 71: 169-180.

31. Schmidt S, Beige S, Walla-Friedel M, Michel MC, Sharma AM, et al. (1997) A polymorphism in the gene for the angiotensin II type 1 receptor is not associated with hypertension. J Hypertens 15: 1385-1388.

32. Shaker OG, Eldemellawy HH, Kassem HH (2009) Angiotensinogen Gene M235t Polymorphism and Coronary Artery Disease in The Egyptian Population A Genetic Association Study. Heart Mirror Journal 3: 1687-6652.

33. Jiang WL, He HW, Yang ZJ (2014) The angiotensinogen gene polymorphism is associated with heart failure among Asians. Sci Rep 4: 4207.

34. Imen T, Grissa MH, Boubaker H, Beltaief K, Messous S, et al. (2015) AGT M235t polymorphism and heart failure in a cohort of Tunisian population: Diagnostic and prognostic value. Int J Clin Exp Med 8(9): 16346-16351.

35. Inoue I, Nakajima T, Williams CS, Quackenbush J, Puryear R, et al. (1997) A nucleotide substitution in the promoter of human angiotensinogen is associated with essential hypertension and affects basal transcription in vitro. J Clin Invest 99: 1786-1797.

36. Ronaghi M, Karamohamed S, Pettersson B, Uhlen M, Nyren P (1996) Rea time DNA sequencing using detection of pyrophosphate release. Anal Biochem 242: 84-89.

37. Pilbrow AP, Palmer BR, Frampton CM, Yandle TG, Troughton RW, et al. (2007) Angiotensinogen M235T and $\mathrm{T} 174 \mathrm{M}$ gene polymorphisms in combination doubles the risk of mortality in heart failure. Hypertension 49: 322-327.

38. Schorr U, Blaschke K, Beige J, Distler A, Sharma AM (1999) Angiotensinogen M235T variant and salt sensitivity in young normotensive Caucasians. Hypertens 17: 475-479.

39. Fang YJ, Deng HB, Thomas GN, Tzang CH, Li CX, et al. (2010) Linkage of angiotensinogen gene polymorphisms with hypertension in a sibling study of Hong Kong Chinese. J Hypertens 28: 1203-1209.

40. Chen S, Zhang L, Wang HW, Wang XY, Li XQ, et al. (2014) The M235 polymorphism in the angiotensinogen gene and heart failure: A Metaanalysis. $J$ Renin Angiotensin Aldosterone Syst 15: 190-195.

41. Marium MS, Hosny F, Medhat $\mathrm{H}$, Mahmoud $\mathrm{H}$, Ayman MAH (2015) Association between the Angiotensinogen (AGT) gene (M235T) polymorphism and Essentia Hypertension in Egyptian patients. The Egyptian Heart Journal 67: 1-5. 